\title{
Optimization of Mesa Etch for a Quasi-Vertical GaN Schottky Barrier Diode (SBD) by Inductively Coupled Plasma (ICP) and Device Characteristics
}

\author{
Yue Sun ${ }^{1,2,3}$, Xuanwu Kang ${ }^{2, *}$, Yingkui Zheng ${ }^{2}$, Ke Wei $^{2}$, Pengfei $\mathrm{Li}^{2}$, Wenbo Wang ${ }^{1}$, \\ Xinyu Liu ${ }^{2}$ and Guoqi Zhang ${ }^{3, *}$ \\ 1 Shenzhen Institute of Wide-Bandgap Semiconductors, Shenzhen 518000, China; y.sun-6@tudelft.nl (Y.S.); \\ wenbo.wang@iwins.org (W.W.) \\ 2 Institute of Microelectronics, Chinese Academy of Sciences, Beijing 100029, China; \\ zhengyingkui@ime.ac.cn (Y.Z.); weike@ime.ac.cn (K.W.); lipengfei@ime.ac.cn (P.L.); xyliu@ime.ac.cn (X.L.) \\ 3 Department of Microelectronics, Delft University of Technology, 2628 CD Delft, The Netherlands \\ * $\quad$ Correspondence: kangxuanwu@ime.ac.cn (X.K.); G.Q.Zhang@tudelft.nl (G.Z.); Tel.: +86-186-0009-6727 (X.K.)
}

Received: 24 February 2020; Accepted: 29 March 2020; Published: 1 April 2020

\begin{abstract}
The optimization of mesa etch for a quasi-vertical gallium nitride (GaN) Schottky barrier diode (SBD) by inductively coupled plasma (ICP) etching was comprehensively investigated in this work, including selection of the etching mask, ICP power, radio frequency (RF) power, ratio of mixed gas, flow rate, and chamber pressure, etc. In particular, the microtrench at the bottom corner of the mesa sidewall was eliminated by a combination of ICP dry etching and tetramethylammonium hydroxide (TMAH) wet treatment. Finally, a highly anisotropic profile of the mesa sidewall was realized by using the optimized etch recipe, and a quasi-vertical GaN SBD was demonstrated, achieving a low reverse current density of $10^{-8} \mathrm{~A} / \mathrm{cm}^{2}$ at $-10 \mathrm{~V}$.
\end{abstract}

Keywords: GaN; inductively coupled plasma (ICP); mesa; sidewall profile; quasi-vertical; Schottky barrier diode (SBD); dry etch

\section{Introduction}

As a wide-bandgap semiconductor material, gallium nitride $(\mathrm{GaN})$ has attracted increasing attention in recent years, attributed to its superior material properties such as wide bandgap, high electron saturation velocity, and high critical electric field [1]. The excellent performance of GaN-based vertical devices has revealed significant potential for high-power and high-frequency applications [2,3]. In addition to the conventional GaN self-standing substrate, epitaxial growth can be carried out on lower-cost and larger-scale foreign substrates (e.g., silicon, sapphire). Therefore, quasi-vertical structures are considered a promising candidate for future GaN-based vertical power devices [4], as shown in Figure 1a,b.

The formation of an active region by the mesa process is the most critical step for quasi-vertical GaN device fabrication. Firstly, the etched sidewall of the mesa was identified as one of the major leakage current paths in quasi-vertical diodes [5]. The leakage current path along the etched sidewall can be reduced by optimization of the etching technique or combination with further surface treatment to reduce plasma damage, leading to improvement of the device breakdown voltage (BV). Secondly, the steep profile of the mesa sidewall allows for reduction of the distance between the anode and cathode electrodes, resulting in a reduction of the series resistance of the Schottky barrier diode (SBD). Therefore, the formation of highly anisotropic profiles of the mesa structure in the etching process is crucial for quasi-vertical GaN devices [6]. Most efforts on the reduction of surface damage and roughness of mesas [7] have been made using inductively coupled plasma (ICP) power, radio frequency 
(RF) power, the ratio of etching gas, flow rate [8-11], and mask selection [12]. Moreover, the steepness of the mesa sidewall has also been investigated using ICP dry etching [13]. However, few works have been reported to eliminate microtrench issues for GaN mesa etching [14].

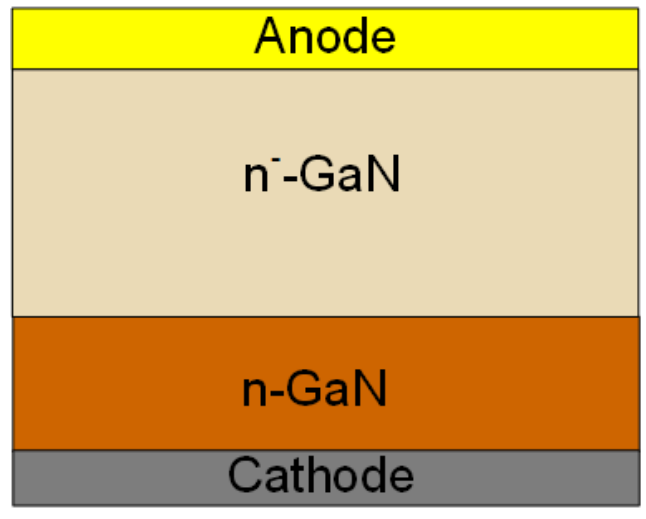

(a)

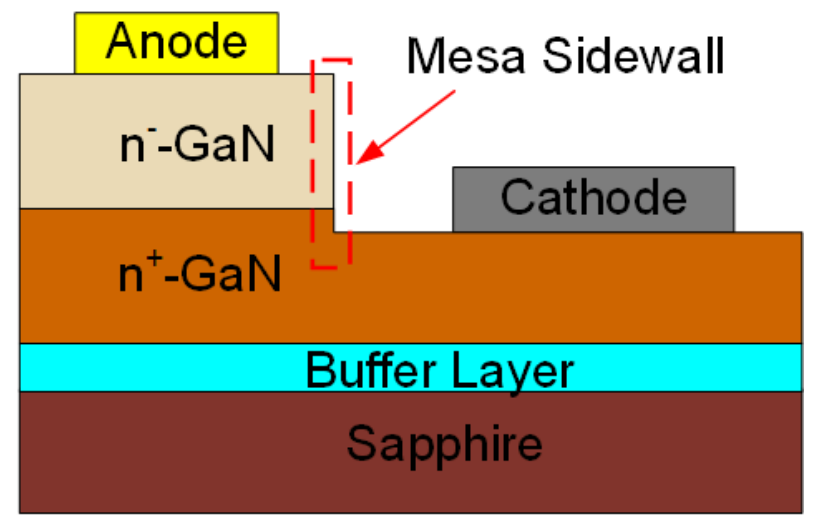

(b)

Figure 1. Schematic cross sections of (a) vertical gallium nitride (GaN) Schottky barrier diodes (SBDs) and (b) quasi-vertical GaN SBDs.

In this paper, we focus on the optimization of the mesa sidewall process to achieve steep, microtrench-free, and low-damage sidewalls, including mask selection, ICP power, RF power, mixed etching gas ratio, flow rate, chamber pressure, etc. Finally, a highly anisotropic profile of the mesa sidewall is realized using the optimized etching recipe, and the device is demonstrated to achieve a low reverse current density under reverse bias. The detailed study is presented below.

\section{Materials and Methods}

The samples used in this experiment were all epitaxially grown on 2-inch sapphire (0001) substrates by metalorganic chemical vapor deposition (MOCVD). n-GaN samples with an epitaxial layer thickness of $4.7 \mu \mathrm{m}$ were used for the etching experiment. Both photoresist (PR) and silicon dioxide $\left(\mathrm{SiO}_{2}\right)$ hard masks were employed for ICP mesa etching in this work. The process flow of mesa etching with the PR mask is illustrated in Figure 2a-d. A thickness of $7 \mu \mathrm{m}$ positive photoresist (AZ4620) was coated, exposed, and developed for patterning, followed by hard baking (post develop baking) in the oven. Finally, a mesa was formed after chlorine-based ICP dry etching. On the other hand, the process flow of mesa etching with the $\mathrm{SiO}_{2}$ hard mask is depicted in Figure 2e-i. A $550 \mathrm{~nm} \mathrm{SiO}{ }_{2}$ mask layer was firstly deposited by plasma-enhanced chemical vapor deposition (PECVD), followed by $1 \mu \mathrm{m}$ reversal photoresist (AZ5214E) coating, exposure, and development. The $\mathrm{SiO}_{2}$ hard mask was then opened by fluorine-based ICP etching. After the pattern was transferred from the $\mathrm{SiO}_{2}$ into the $\mathrm{GaN}$ layer and the mesa structure was formed by chlorine-based ICP etching, the $\mathrm{SiO}_{2}$ mask was stripped using a buffer of etchant (BOE) solution. In this experiment, the ICP power, RF power, pressure, and ratio of mixed etching gas could be adjusted to obtain highly anisotropic profiles.

Then, the optimized etching recipe was applied for quasi-vertical GaN SBD fabrication. The GaN epi-layer was grown on 2-inch sapphire (0001) and consisted of a $2 \mu \mathrm{m}$ undoped buffer layer, a $3 \mu \mathrm{m} \mathrm{n}^{+}-\mathrm{GaN}$ conducting layer (Si doping: $5 \times 10^{18} \mathrm{~cm}^{-3}$ ), and a $1 \mu \mathrm{m} \mathrm{n}^{-}-\mathrm{GaN}$ drift layer (Si doping: $1 \times 10^{16} \mathrm{~cm}^{-3}$ ). After the mesa structure was formed by ICP etching, samples were immersed in tetramethylammonium hydroxide (TMAH) at $45^{\circ} \mathrm{C}$ for $30 \mathrm{~min}$. Then, Ti/Al/Ni/Au was deposited and annealed to form ohmic contacts with the $\mathrm{n}^{+}-\mathrm{GaN}$ layer, which acted as the cathode electrode. Finally, a Ni/Au electrode with a radius of $70 \mu \mathrm{m}$ was deposited to form a Schottky contact with the $\mathrm{n}^{-}-\mathrm{GaN}$ drift layer, which acted as the anode electrode. 


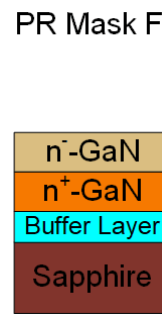

(a)

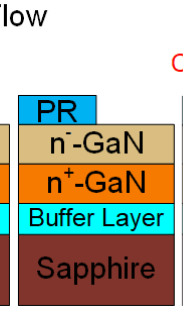

(b)

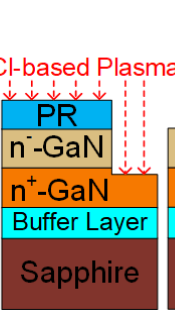

(c)

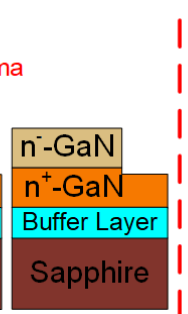

(d)

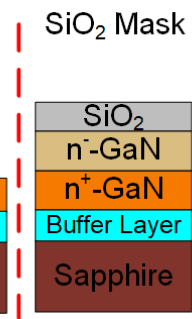

(e)

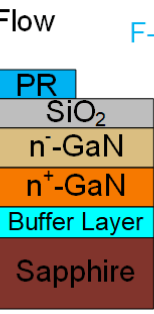

(f)

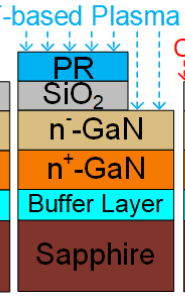

(g)

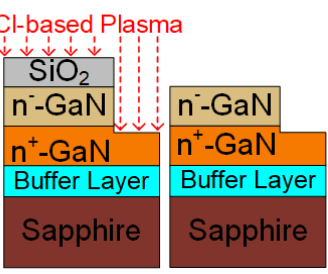

(h)

(i)

Figure 2. Fabrication steps of mesa etching with photoresist (PR) as a mask. (a) Epitaxial structure of the GaN sample; (b) PR mask on GaN; (c) chlorine-based mesa etching; (d) stripping of the PR. Fabrication steps of the $\mathrm{SiO}_{2}$-masked $\mathrm{GaN}$ mesa etching; (e) $\mathrm{SiO}_{2}$ hard mask deposition on the $\mathrm{GaN}$ sample; (f) PR mask on $\mathrm{SiO}_{2}$; (g) hard mask etching by fluorine-based plasma; (h) chlorine-based mesa etching; (i) Stripping of the $\mathrm{SiO}_{2}$ hard mask.

\section{Results and Discussion}

$\mathrm{Cl}_{2}$ was used as a primary etching gas for the PR-masked etching samples [15]. To investigate the impact of ICP and RF power on the etched sidewall profile, the chamber pressure, flow rate of $\mathrm{Cl}_{2}$, and etching time were kept identical. The detailed etching parameters and etching rate results are listed in Table 1.

Table 1. Result of PR-masked GaN samples under different etching conditions.

\begin{tabular}{ccccccc}
\hline Sample & $\begin{array}{c}\text { ICP Power } \\
(\mathbf{W})\end{array}$ & $\begin{array}{c}\text { RF Power } \\
\mathbf{( W )}\end{array}$ & $\begin{array}{c}\text { Pressure } \\
\mathbf{( P a )}\end{array}$ & $\begin{array}{c}\mathbf{C l}_{\mathbf{2}} \\
\mathbf{( s c c m})\end{array}$ & $\begin{array}{c}\text { GaN Etching } \\
\text { Rate }(\mathbf{n m} / \mathbf{m i n})\end{array}$ & $\boldsymbol{\theta}_{\text {GaN }}$ \\
\hline Reference & 360 & 63 & 1.5 & 130 & 120 & $25.0^{\circ}$ \\
High RF & 360 & 210 & 1.5 & 130 & 537 & - \\
High ICP & 540 & 63 & 1.5 & 130 & 550 & - \\
\hline
\end{tabular}

$\theta_{\mathrm{GaN}}$ is the etched GaN sidewall angle. RF power is the radio frequency power. ICP power is the inductively coupled plasma power.

The etching rate of GaN was observed to increase from $120 \mathrm{~nm} / \mathrm{min}$ to $550 \mathrm{~nm} / \mathrm{min}$ when the ICP power varied from $360 \mathrm{~W}$ to $540 \mathrm{~W}$. This increased etching rate is mainly attributed to the highly reactive chlorine ion (chemical component) density increasing under high ICP power [16]. In addition, the etching rate of $\mathrm{GaN}$ was observed to be positively proportional to the RF power as well. The etching rate increased from $120 \mathrm{~nm} / \mathrm{min}$ at $63 \mathrm{~W}$ to $537 \mathrm{~nm} / \mathrm{min}$ at $210 \mathrm{~W}$. The increased RF power enhances the physical sputtering of $\mathrm{GaN}$ etching by heavy radicals; then, the enhanced physical bombardment helps to break the Ga-N bonds, speeding up the chemical etching process $[17,18]$. As shown in Figure 3a, the reference sample was observed to have a smooth sidewall profile. However, numerous pillars emerged on the sidewall for samples with high RF and those with high ICP power, as shown in Figure $3 b$,c. Rawal et al. also reported similar observations that mesa edges were damaged by chlorine ions caused by $\mathrm{BCl}_{3} / \mathrm{Cl}_{2}$ discharge during ICP etching [16]. This is due to the photoresist mask erosion caused by enhanced physical bombardment and chemical components; the distorted pattern is then transferred to the $\mathrm{GaN}$, resulting in deteriorated mesa sidewall morphology [9].

A high-temperature hard baking (post-develop baking) prior to the ICP etching can help to eliminate the PR burning/erosion issues [19]. The baking temperature was varied from $100^{\circ} \mathrm{C}$ to $180^{\circ} \mathrm{C}$, followed by ICP etching under ICP power of $360 \mathrm{~W}$, RF power of $63 \mathrm{~W}$, pressure of $1.5 \mathrm{~Pa}$, and $\mathrm{Cl}_{2}$ flow rate of $130 \mathrm{sccm}$. The detailed results are listed in Table 2. As shown in Figure $4 \mathrm{a}-\mathrm{c}$, the slope of the mesa sidewall decreased with increasing PR baking temperature, which is due to edge bulge formation at the photoresist pattern as the baking temperature increased, resulting in photoresist sidewall profile transformation and pattern transfer onto the GaN $[20,21]$. Although baking at a high temperature can help to obtain a smooth mesa sidewall, there are a few drawbacks when the baking temperature 
applied is above the glass transition temperature $\left(120-130{ }^{\circ} \mathrm{C}\right)$ of the photoresist, such as significant oblique sidewall profile formation, hard striping [22], and volume loss of PR [23].

Table 2. Etched results with different hard baking temperatures.

\begin{tabular}{cccccccc}
\hline Sample & $\begin{array}{c}\text { ICP Power } \\
(\mathbf{W})\end{array}$ & $\begin{array}{c}\text { RF Power } \\
(\mathbf{W})\end{array}$ & $\begin{array}{c}\text { Pressure } \\
\mathbf{( P a )}\end{array}$ & $\begin{array}{c}\mathbf{C l}_{\mathbf{2}} \\
(\mathbf{s c c m})\end{array}$ & $\begin{array}{c}\text { GaN Etching } \\
\text { Rate }(\mathbf{n m} / \mathbf{m i n})\end{array}$ & $\boldsymbol{\theta}_{\mathbf{G a N}}$ & $\begin{array}{c}\mathbf{T} \\
\left({ }^{\circ} \mathbf{C}\right)\end{array}$ \\
\hline 1 & 360 & 63 & 1.5 & 130 & 135 & $23.0^{\circ}$ & 100 \\
2 & 360 & 63 & 1.5 & 130 & 123 & $17.0^{\circ}$ & 150 \\
3 & 360 & 63 & 1.5 & 130 & 117 & $15.0^{\circ}$ & 180 \\
\hline
\end{tabular}

$\theta_{\mathrm{GaN}}$ is the etched GaN sidewall angle. T is the photoresist hard baking temperature.

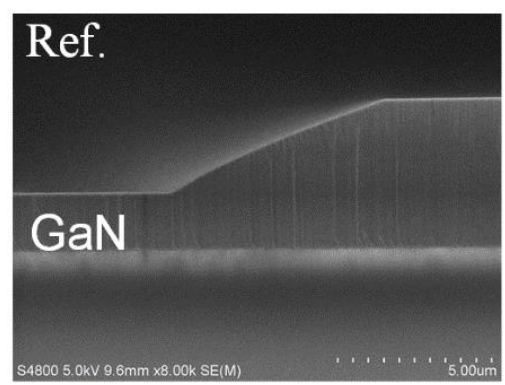

(a)

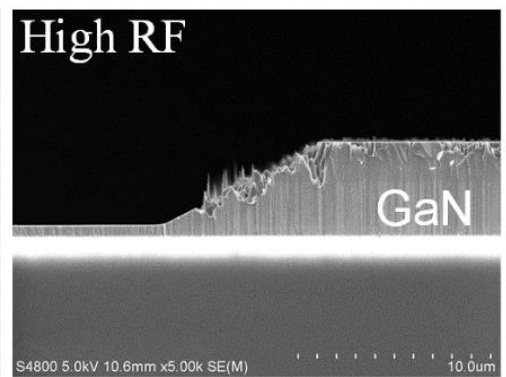

(b)

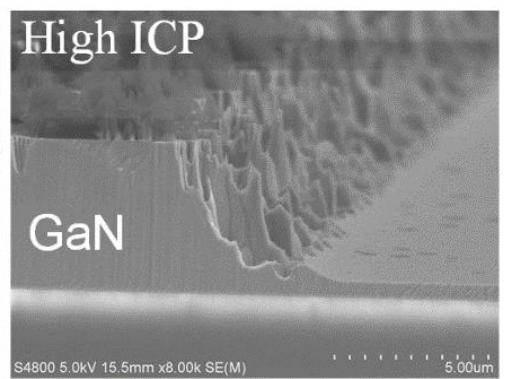

(c)

Figure 3. Cross scanning electron microscope (SEM) photomicrographs of GaN mesa sidewalls etched with a PR mask under $\mathrm{Cl}_{2}$ plasma conditions with 1.5 Pa pressure and $130 \mathrm{sccm}$ flow rate. (a) Reference sample. (b) High RF-power etched sample. (c) High ICP-power etched sample.

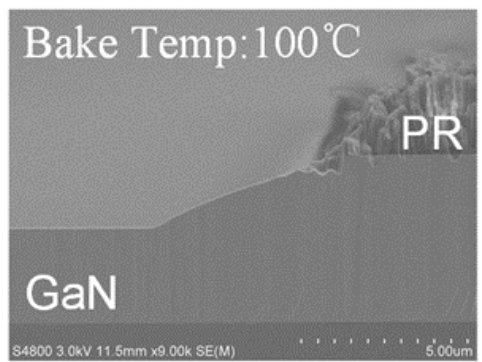

(a)

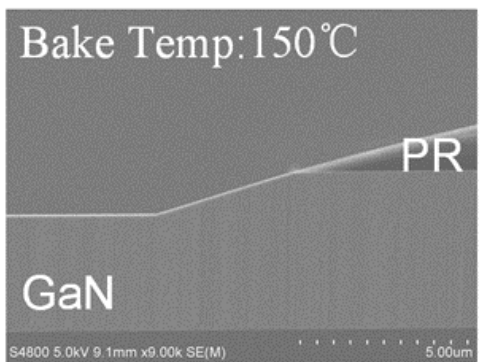

(b)

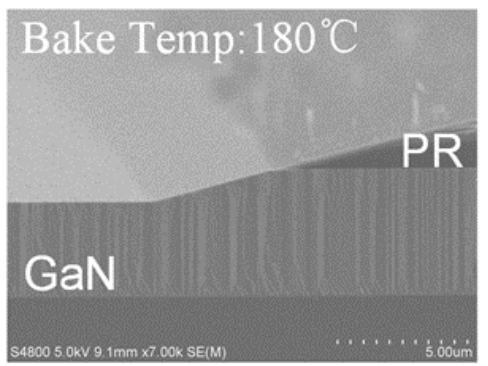

(c)

Figure 4. Cross SEM sidewall profiles of photoresist (AZ4620)-masked GaN samples after etching with different hard baking temperatures. (a) $100{ }^{\circ} \mathrm{C}$; (b) $150{ }^{\circ} \mathrm{C}$; (c) $180{ }^{\circ} \mathrm{C}$.

Although a smooth mesa sidewall was obtained with the PR mask, a steep sidewall is necessary to reduce the series resistance of a quasi-vertical SBD. A hard mask is more suitable for deep etching of GaN devices, because the etching selectivity of GaN/hard mask is relatively high [12]. To achieve a steep mesa sidewall, we used $\mathrm{SiO}_{2}$ as the hard mask in all of the following experiments. Figure 5a shows a cross section of photoresist (AZ5214E) after development of the mesa pattern. Figure 5b,c shows a cross-section of the $\mathrm{SiO}_{2}$ hard mask with PR on top and without PR, respectively, after fluorine-based ICP etching of the $\mathrm{SiO}_{2}$ hard mask.

The impact of etching time on the mesa sidewall profile, etching rates, and etching selectivity was also investigated, while keeping the ICP power, RF power, pressure, and flow rate of $\mathrm{Cl}_{2}$ at $360 \mathrm{~W}$, $63 \mathrm{~W}, 1.5 \mathrm{~Pa}$, and $130 \mathrm{sccm}$, respectively. The cross sections of sidewalls with varying etching time are shown in Figure 6. With increasing etching time, a microtrench emerged at the bottom corner of the mesa sidewall, as shown in Figure 6b,c. In addition, a slight bowing problem was observed at the mesa sidewall after $7 \mathrm{~min}$ of etching. The bowing phenomenon is related with a variety of factors, e.g., non-directional incident ions and isotropic spontaneous chemical etching [24]. 


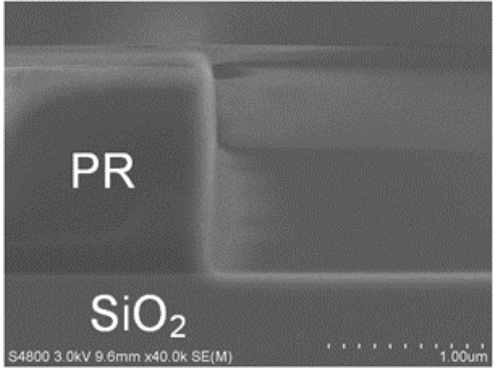

(a)

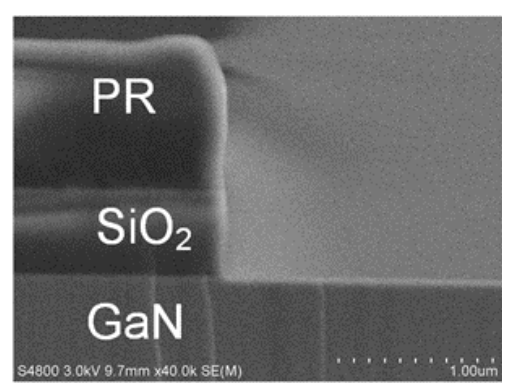

(b)

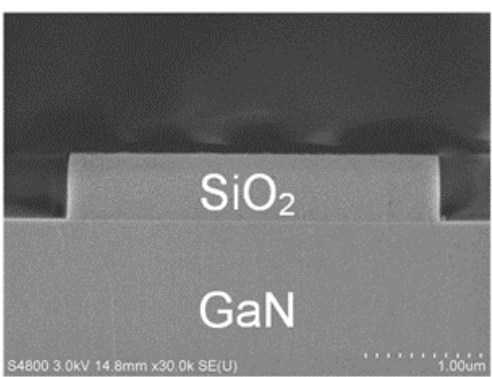

(c)

Figure 5. Cross SEM images of the sidewall of (a) photoresist (AZ5214E) and of (b) $\mathrm{SiO}_{2}$ hard mask with PR on top and (c) without PR.

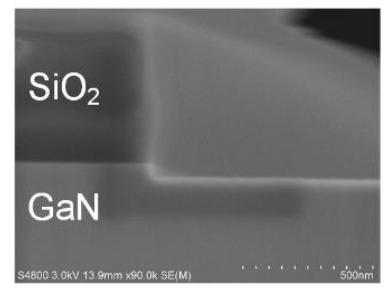

(a)

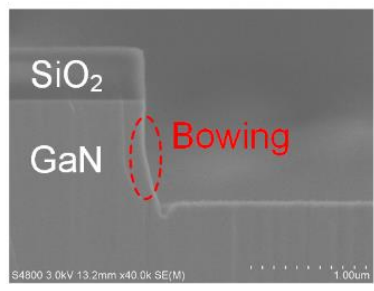

(b)

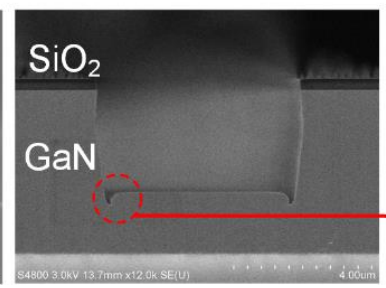

(c)

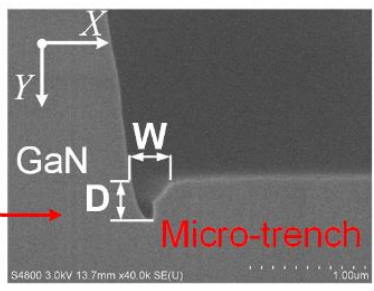

(d)

Figure 6. (a-c) SEM images of sidewall profiles of $\mathrm{SiO}_{2}$-masked $\mathrm{GaN}$ with different etch times: (a) $30 \mathrm{~s}$; (b) $7 \mathrm{~min}$; (c) $20 \mathrm{~min}$. The marked corner was chosen to show the details of the microtrench. (d) SEM image of the microtrench at the bottom corner of the mesa. D and W are the depth and width of the microtrench, respectively.

Figure 7a shows the GaN etching rates and etching selectivity of $\mathrm{GaN} / \mathrm{SiO}_{2}$ with etching time. Both etching rate and selectivity have a weak dependency on etching time, with values of about 120 and $9.8 \mathrm{~nm} / \mathrm{min}$, respectively. As shown in Figure $7 \mathrm{~b}$, with increasing etching time, the depth and width of the microtrench increased. The etching rate of the microtrench along the $\mathrm{Y}$ direction slightly increased with etching time, and the etching rate along the $X$ direction showed nearly no change. A number of ions were incident along the bowing sidewall and then focused on the bottom corner of the sidewall, leading to an increased etching rate in the $Y$ direction of the microtrench after a long etching time [24,25].

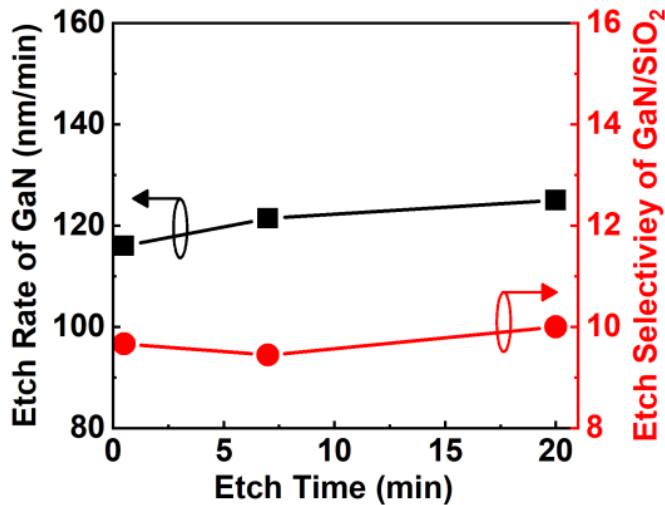

(a)

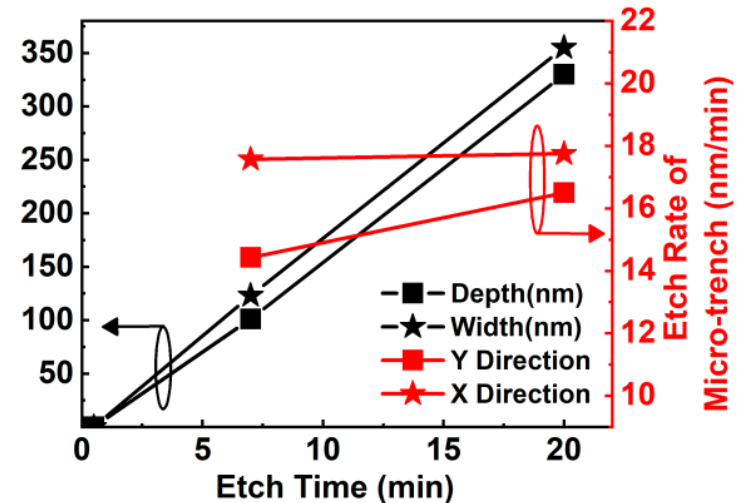

(b)

Figure 7. (a) Etching rate of $\mathrm{GaN}$ and etching selectivity of $\mathrm{GaN}$ over $\mathrm{SiO}_{2}$ as a function of etching time. (b) The effect of etching time on the depth and width of the microtrench, and the etching rates of the microtrench in the $\mathrm{X}$ and $\mathrm{Y}$ directions.

As seen in Figure $8 \mathrm{a}$, the etching rate of $\mathrm{GaN}$ is a strong function of RF power and increased from $86 \mathrm{~nm} / \mathrm{min}$ to $380 \mathrm{~nm} / \mathrm{min}$ when RF power increased from $42 \mathrm{~W}$ to $168 \mathrm{~W}$ at $1.5 \mathrm{~Pa}$ pressure, $360 \mathrm{~W}$ 
ICP power, and a $\mathrm{Cl}_{2}$ flow rate of $130 \mathrm{sccm}$. With increased RF power from $42 \mathrm{~W}$ to $168 \mathrm{~W}$, the direct current (DC) bias increased from $-40 \mathrm{~V}$ to $-155 \mathrm{~V}$. The increased DC bias increases the energy of ions and enhances the physical etching components, which can further increase the chemical etching component $[16,26]$. Figure $8 \mathrm{~b}$ shows that the etching selectivity of $\mathrm{GaN}$ over $\mathrm{SiO}_{2}$ was reduced slightly as RF power increased. As shown in Figure 8c, the etching rate of the microtrench in either the $X$ or $Y$ direction increased with increasing RF power due to the strong physical bombardment [14]. With a low RF power of $63 \mathrm{~W}$, the microtrench could be reduced. However, it deteriorated when the RF power increased to $168 \mathrm{~W}$, as shown in the inset.

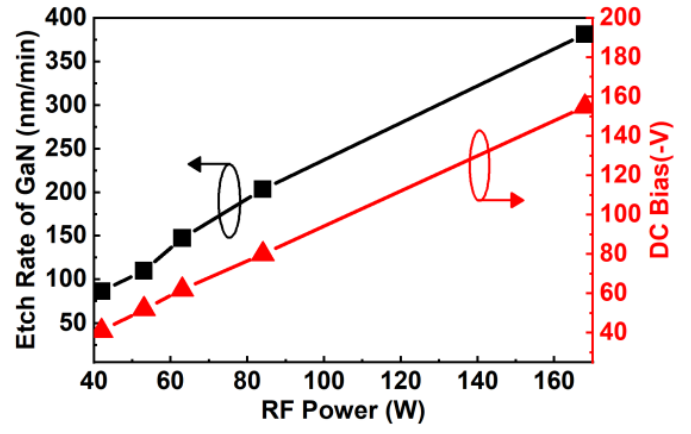

(a)

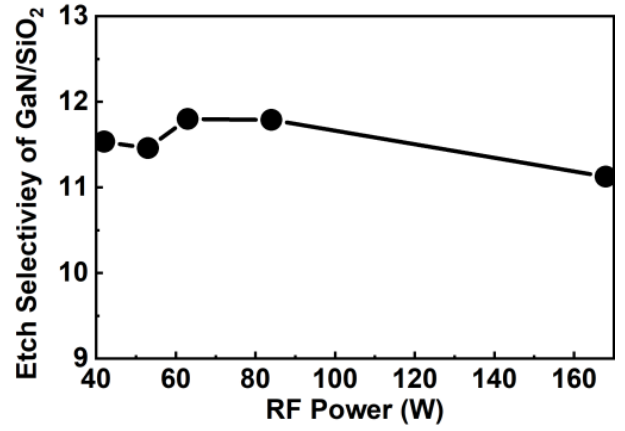

(b)

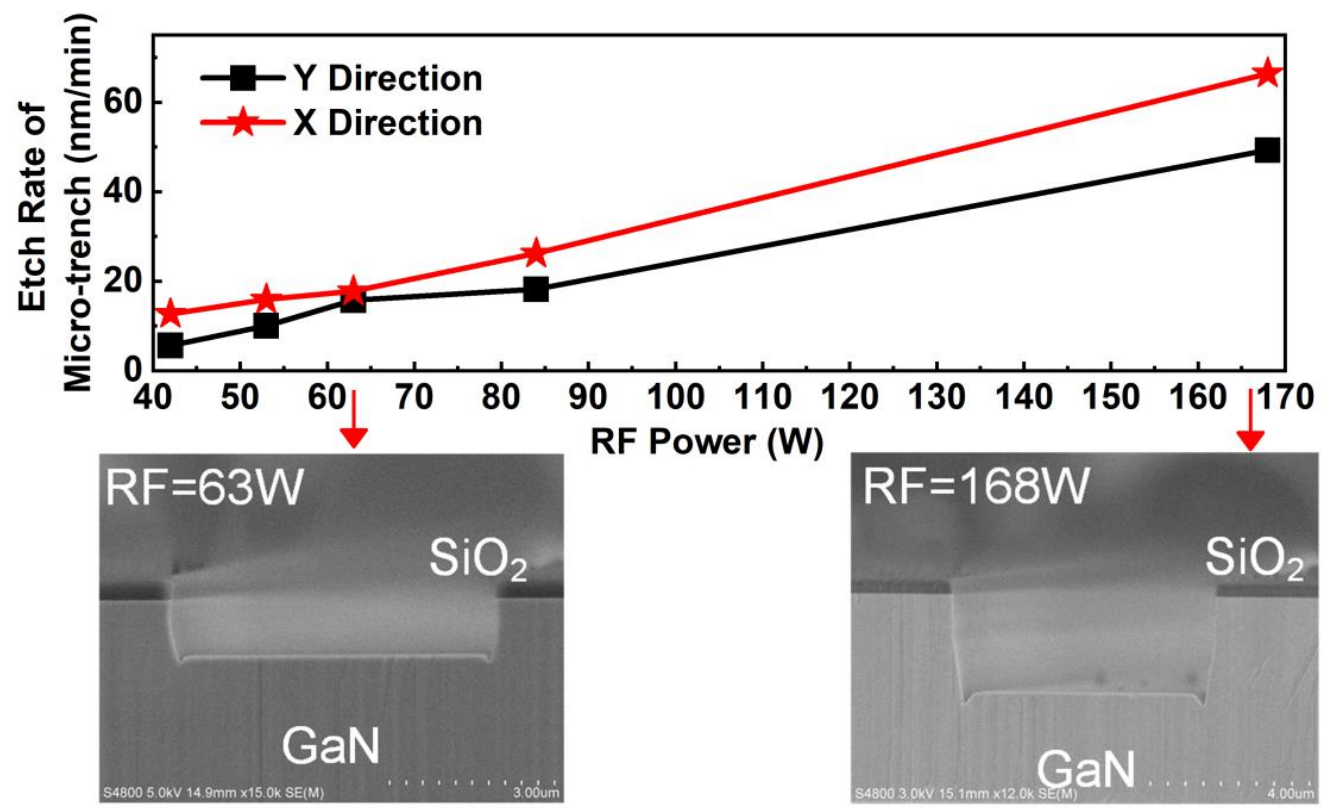

(c)

Figure 8. (a) Etching rate of $\mathrm{GaN}$ and direct current (DC) bias as a function of RF power. (b) Etching selectivity of $\mathrm{GaN}$ over $\mathrm{SiO}_{2}$ as a function of RF power. (c) The effect of RF power on etching rates of the microtrench in the $\mathrm{X}$ and $\mathrm{Y}$ directions. The insets of (c) show cross SEM images of samples etched with $63 \mathrm{~W}$ and $168 \mathrm{~W}$ RF power.

As shown in Figure 9a, the etching rate of GaN increased monotonically with increasing ICP power under etching conditions of $42 \mathrm{~W}$ RF power, $130 \mathrm{sccm} \mathrm{Cl}$ flow rate, and $1.5 \mathrm{~Pa}$ pressure. The etching rate increased from $84 \mathrm{~nm} / \mathrm{min}$ to $180 \mathrm{~nm} / \mathrm{min}$ when the ICP power increased from $360 \mathrm{~W}$ to $540 \mathrm{~W}$. The increase in the GaN etching rate is attributed to enhanced chemical etching by increased $\mathrm{Cl}$ ion flux density [27]. The observation that the DC bias increases with increasing ICP power is mainly due to the ICP tool operating in capacitive coupling mode (called E mode [28]). When the tool is operated in this mode, ion density is low at low ICP power [29]. Cooke et al. [30], Zhou et al. [27], and Qiu et al. [31] 
reported similar dependences of DC bias on ICP power. Figure $9 \mathrm{~b}$ shows that the selectivity increased slightly as ICP power increased. As shown in Figure 9c, the etching rates of the microtrench increased from $3 \mathrm{~nm} / \mathrm{min}$ to $5 \mathrm{~nm} / \mathrm{min}$ in the $Y$ direction and from $9 \mathrm{~nm} / \mathrm{min}$ to $13 \mathrm{~nm} / \mathrm{min}$ in the $X$ direction when the ICP power increased from $360 \mathrm{~W}$ to $450 \mathrm{~W}$. Then, the etching rates rocketed to $16 \mathrm{~nm} / \mathrm{min}$ in the $\mathrm{Y}$ direction and $25 \mathrm{~nm} / \mathrm{min}$ in the $\mathrm{X}$ direction at $540 \mathrm{~W} \mathrm{ICP}$ power. The reason for this is that the sidewall profile becomes bowed at high ICP power when $\mathrm{Cl}_{2}$ is used as the etching gas, then the bowed sidewall profile leads to the accumulation of ions at the corner of the mesa bottom, causing an increase in the microtrench etching rate [32].

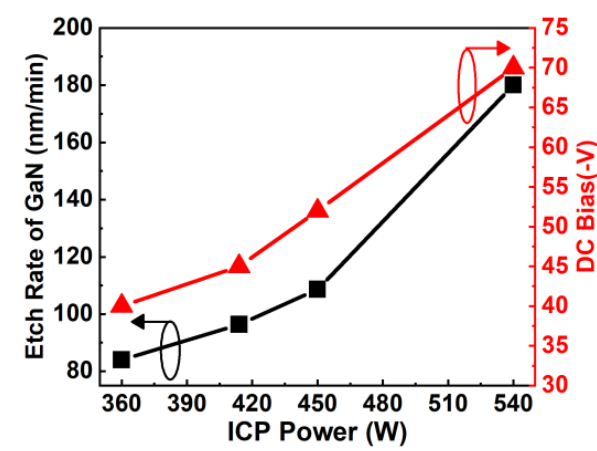

(a)

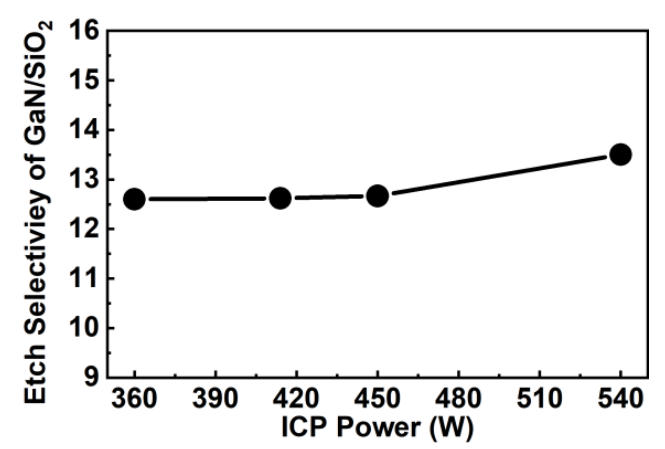

(b)

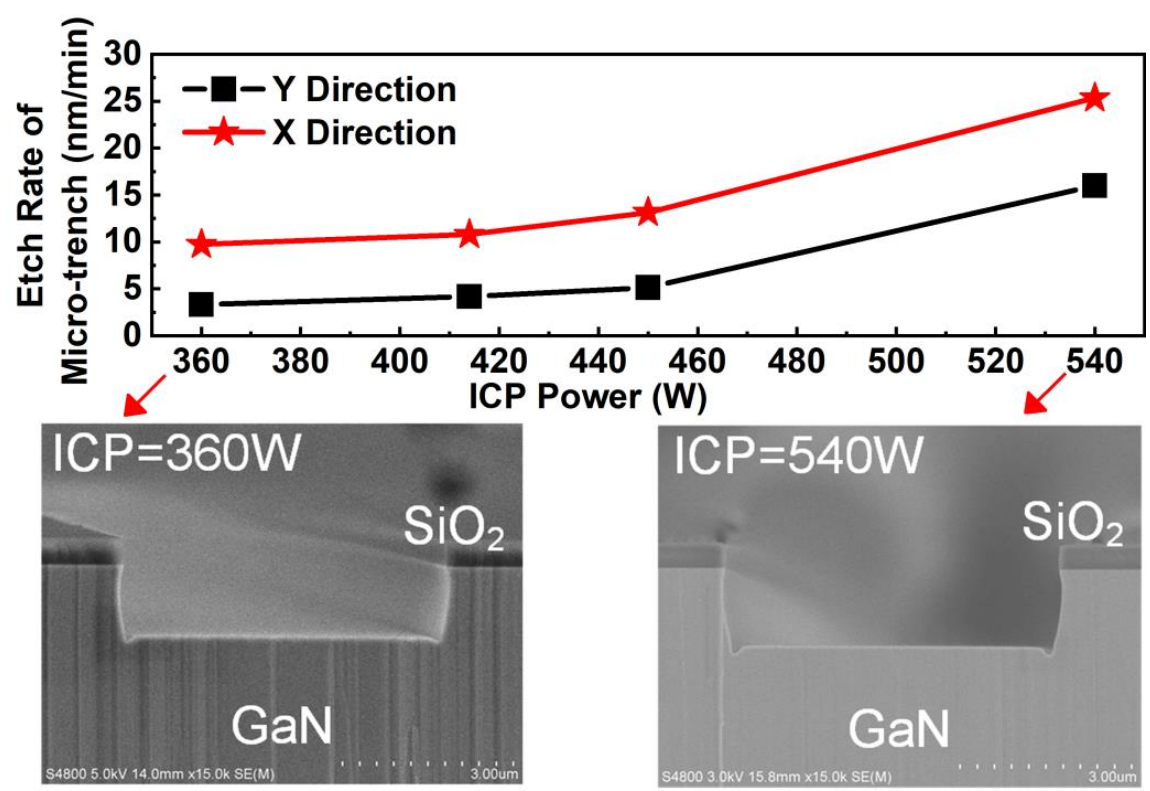

(c)

Figure 9. (a) Etching rate of GaN and DC bias as a function of ICP power. (b) Etching selectivity of GaN over $\mathrm{SiO}_{2}$ as a function of ICP power. (c) The effect of ICP power on the etching rates of the microtrench in the $\mathrm{X}$ and $\mathrm{Y}$ directions. The insets of (c) show cross SEM images for samples etched with $360 \mathrm{~W}$ and $540 \mathrm{~W}$ ICP power.

$\mathrm{BCl}_{3}$ as an additive in the etching gas can increase the etching rate of $\mathrm{GaN}$ [33]. Thus, in order to improve the etching rate of $\mathrm{GaN}$ and investigate the mesa sidewall profile, the percentage of $\mathrm{BCl}_{3}$ in the $\mathrm{Cl}_{2} / \mathrm{BCl}_{3}$ gas mixture was varied from $0 \%$ to $39 \%$ with fixed ICP power of $540 \mathrm{~W}$, RF power of $168 \mathrm{~W}$, total gas flow of $130 \mathrm{sccm}$, and pressure of $1.5 \mathrm{~Pa}$. Figure 10a shows that the etching rate of $\mathrm{GaN}$ increased with increasing $\mathrm{BCl}_{3}$ concentration in the $\mathrm{Cl}_{2} / \mathrm{BCl}_{3}$ gas mixture up to $9 \% \mathrm{BCl}_{3}$, where the maximum etching rate was reached, then decreased from $415 \mathrm{~nm} / \mathrm{min}$ to $231 \mathrm{~nm} / \mathrm{min}$ as the $\mathrm{BCl}_{3}$ concentration further increased, similar to other reports [34,35]. When the $\mathrm{BCl}_{3}$ concentration was below $10 \%$, the $\mathrm{Cl}$ radicals and $\mathrm{Cl}^{+}$positive ions showed an increasing tendency in the reaction 
chamber as the $\mathrm{BCl}_{3}$ concentration increased [33], intensifying the ion bombardment and chemical etching process, resulting in the increase of the $\mathrm{GaN}$ etching rate. However, the $\mathrm{Cl}_{\text {and }} \mathrm{Cl}^{+}$ion density decreased with increasing $\mathrm{BCl}_{3}$ concentration when the concentration was above $10 \%$, resulting in a reduction of the etching rates of $\mathrm{GaN}$ and $\mathrm{DC}$ bias [36]. The etching selectivity of $\mathrm{GaN}$ over $\mathrm{SiO}_{2}$ was significantly reduced from 10.5 to 4 as the $\mathrm{BCl}_{3}$ concentration increased (as shown in Figure 10b). This is attributed to the positive $\mathrm{BCl}_{2}{ }^{+}$ion density increasing as the $\mathrm{BCl}_{3}$ concentration increases, leading to an increase in the $\mathrm{SiO}_{2}$ mask etching rate by the formation of $\mathrm{BCl}_{x} \mathrm{O}_{y}$ in the $\mathrm{SiO}_{2}[37,38]$. As shown in Figure 10c, the etching rates of the microtrench slightly increased with the $\mathrm{BCl}_{3}$ concentration up to $9 \%$, then decreased further at $33 \% \mathrm{BCl}_{3}$ and finally vanished at $39 \%$ in both the $\mathrm{X}$ and $\mathrm{Y}$ directions. A significant reduction in the microtrench can be observed in the inset SEM image in Figure 10c as the $\mathrm{BCl}_{3}$ concentration increases. The reduction of the microtrench phenomenon is related to the sloped sidewall. With such a sloped sidewall, most ions can be reflected to a position away from the bottom corner of the mesa [39]; thus, less physical bombardment accumulates in the bottom corner of the mesa. The sloped sidewall profile might be attributed to the reduction of etching selectivity of GaN over $\mathrm{SiO}_{2}$ in the case of highly anisotropic etching [40]. In addition, pillars were observed in the bottom of the mesa, caused by the spontaneous oxidation of dislocations, inhibiting Cl-based dry etching [41]. In this study, flow rates of $9 \% \mathrm{BCl}_{3}$ concentration were considered a good trade-off in terms of several aspects, such as etching rate, steepness of the sidewall, pillar phenomenon, and microtrench effect.

Figure 11a shows the impact of chamber pressure on the etching rate of $\mathrm{GaN}$ and DC bias. The ICP power, RF power, and flow rates of $\mathrm{Cl}_{2} / \mathrm{BCl}_{3}$ were set at constant values of $540 \mathrm{~W}, 168 \mathrm{~W}$, and $118 \mathrm{sccm} / 12 \mathrm{sccm}\left(\mathrm{Cl}_{2} / 9 \% \mathrm{BCl}_{3}\right)$, respectively. The etching rate of $\mathrm{GaN}$ slightly increased from $416 \mathrm{~nm} / \mathrm{min}$ to $440 \mathrm{~nm} / \mathrm{min}$ with pressure up to $1.5 \mathrm{~Pa}$, and DC bias was decreased as the pressure increased, reaching a minimum value of $-115 \mathrm{~V}$ at $1.5 \mathrm{~Pa}$. When pressure increases, the mean free path of reactive radicals is reduced, followed by an increase of inter-atom collision ionization [14,27]. Therefore, the etching rate of GaN increased with increasing ion flux and the DC bias decreased as the RF power was kept at a constant value [30]. As shown in Figure 11b, the etching selectivity of $\mathrm{GaN} / \mathrm{SiO}_{2}$ increased monotonically as the chamber pressure increased, similar to findings by Wang et al. [42]. Figure 11c shows that etching rates of the microtrench along both the $X$ and $Y$ directions decreased with increased pressure. The etching rate in the $X$ direction has higher dependency on chamber pressure than that in the $Y$ direction, which is attributed to the irregular distribution of incoming ion angles [39]. Therefore, high chamber pressure is preferred to obtain high etching selectivity.

The GaN mesa structure was finalized with optimized conditions of $360 \mathrm{~W}$ ICP power, $42 \mathrm{~W}$ RF power, $118 \mathrm{sccm} / 12 \mathrm{sccm}$ flow rate of $\mathrm{Cl}_{2} / \mathrm{BCl}_{3}$ mixture gas, and 1.5 Pa pressure, approaching a near- $90^{\circ}$ steep sidewall with a tiny microtrench and a slightly rough surface, as shown in Figure 12a,b. The etching rate of $\mathrm{GaN}$ was near $120 \mathrm{~nm} / \mathrm{min}$ and the selectivity of $\mathrm{GaN}$ over $\mathrm{SiO}_{2}$ was 10 . The etching depth was near $1.2 \mu \mathrm{m}$ by adjusting etching time. Figure 12c,d shows cross SEM images of the sidewall and surface after dipping in $15 \% \mathrm{TMAH}$ solution at $45^{\circ} \mathrm{C}$ for $30 \mathrm{~min}$. The sidewall was near $90^{\circ}$ steep and the surface was smoother after TMAH wet treatment. This is due to the sidewall being etched preferentially in anisotropic wet etching solution [43-45].

Finally, quasi-vertical GaN-on-sapphire SBDs with a $1 \mu \mathrm{m} \mathrm{n}^{-}-\mathrm{GaN}$ drift layer and a $3 \mu \mathrm{m} \mathrm{n}^{+}-\mathrm{GaN}$ conducting layer were fabricated with a $1.2 \mu \mathrm{m}$ deep mesa. The forward and reverse characteristics are shown in Figure 13a,b, respectively. Both of the samples achieved a high forward current density of $1000 \mathrm{~A} / \mathrm{cm}^{2}$ at $3 \mathrm{~V}$, while the optimized sample had a reverse leakage current density of $10^{-8} \mathrm{~A} / \mathrm{cm}^{2}$ at $-10 \mathrm{~V}$, which is 2 orders of magnitude lower than that of the non-optimized one. The ideality factor of nearly 1 indicates less of a trapping effect, both in bulk and interface. Moreover, the state-of-the-art low reverse leakage current indicates that the damage to the mesa sidewall is low [46-49]. The leakage current in this work is much lower than that in our previous work with a low-damage etching technique, in which a device was fabricated based on $\mathrm{AlGaN} / \mathrm{GaN}$ heterostructures [50]. Therefore, we suggest that the smooth and low-damage mesa sidewall etching and wet treatment probably contribute to this extremely low leakage current [5]. 


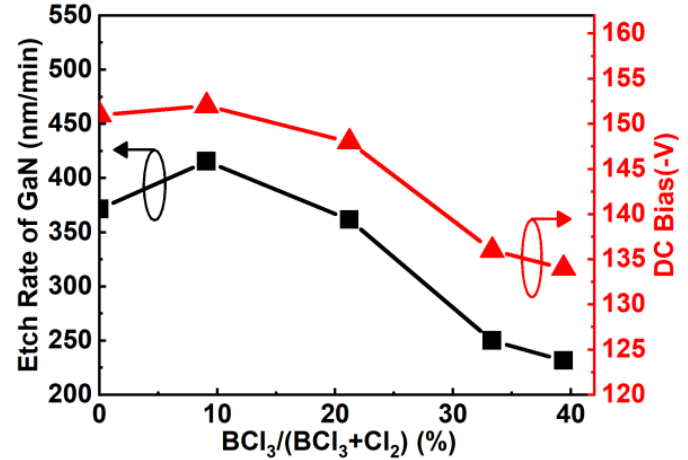

(a)

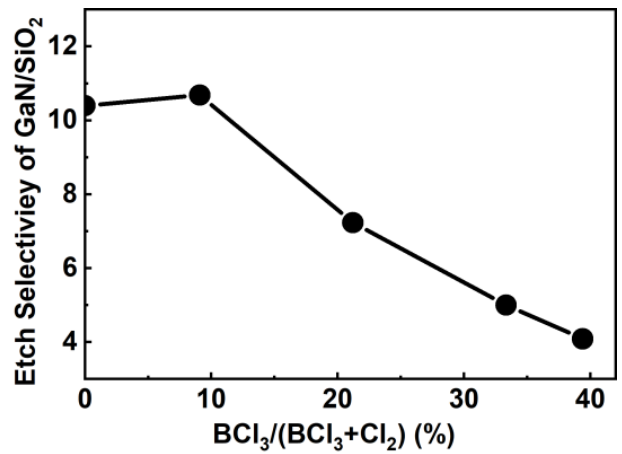

(b)

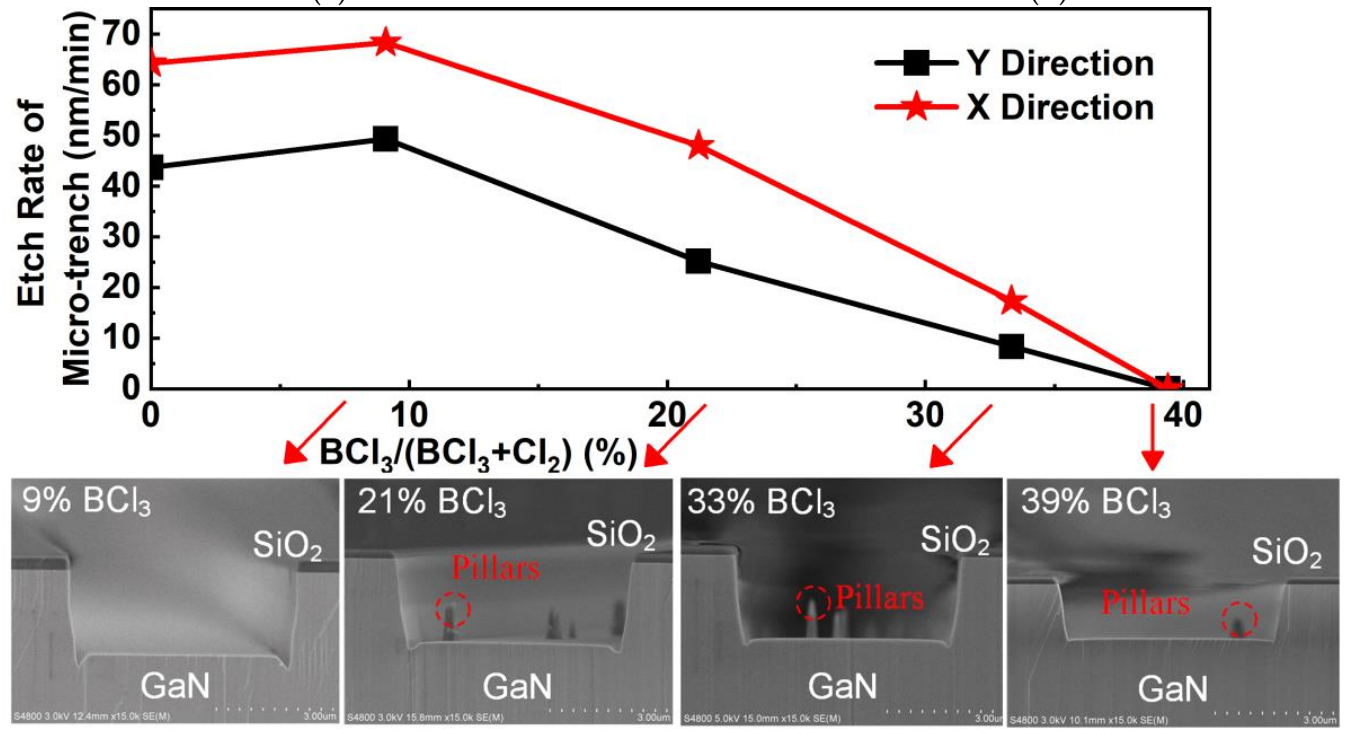

(c)

Figure 10. (a) Etching rate of $\mathrm{GaN}$ and $\mathrm{DC}$ bias as a function of $\mathrm{BCl}_{3}$ content in the $\mathrm{Cl}_{2} / \mathrm{BCl}_{3}$ gas mixture. (b) Etching selectivity of $\mathrm{GaN}$ over $\mathrm{SiO}_{2}$ as a function of $\mathrm{BCl}_{3}$ content in the $\mathrm{Cl}_{2} / \mathrm{BCl}_{3}$ gas mixture. (c) The effect of $\mathrm{BCl}_{3}$ content in the $\mathrm{Cl}_{2} / \mathrm{BCl}_{3}$ gas mixture on etching rates of the microtrench in the $X$ and $Y$ directions. The insets of (c) show cross SEM images for samples etched with different $\mathrm{BCl}_{3}$ concentrations.

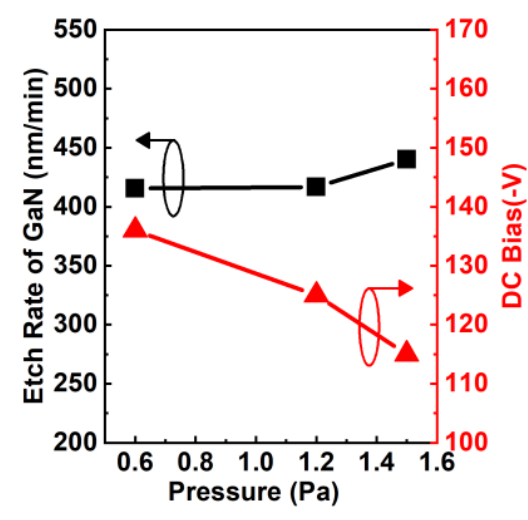

(a)

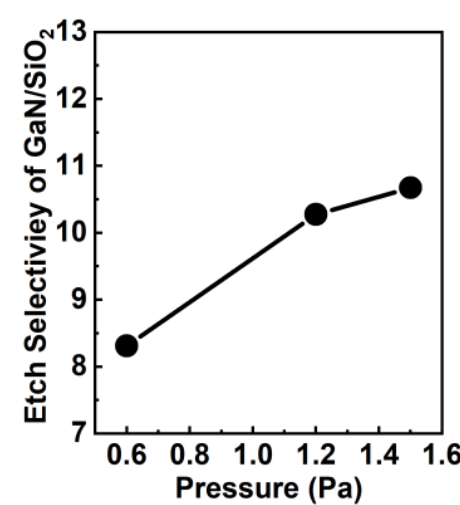

(b)

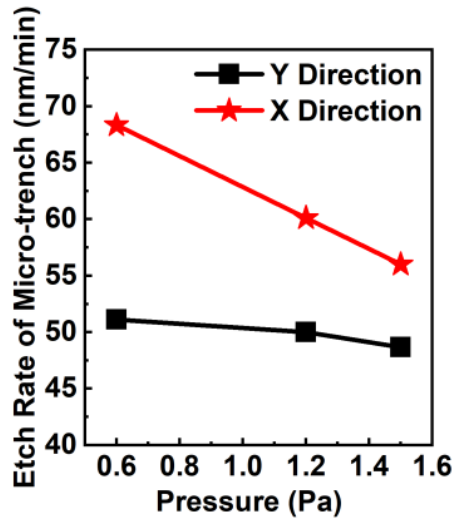

(c)

Figure 11. (a) Etching rate of GaN and DC bias as a function of pressure. (b) Etching selectivity of GaN over $\mathrm{SiO}_{2}$ as a function of pressure. (c) The effect of pressure on etching rates of the microtrench in the $\mathrm{X}$ and $\mathrm{Y}$ directions. 


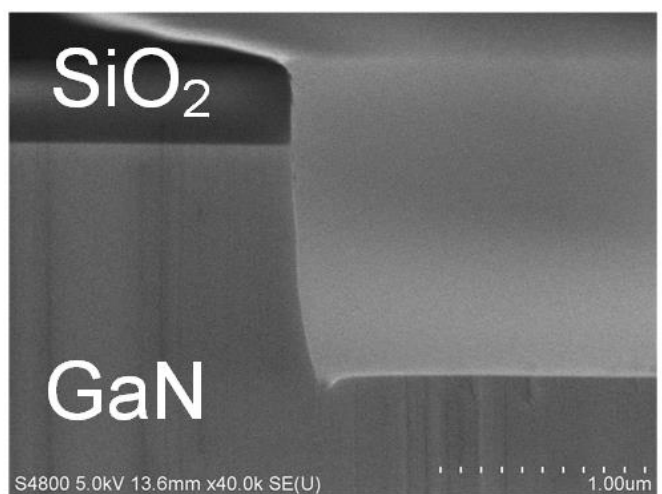

(a)

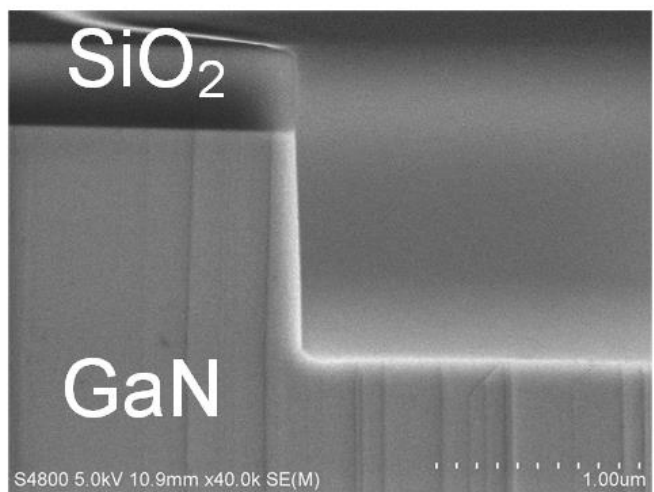

(c)

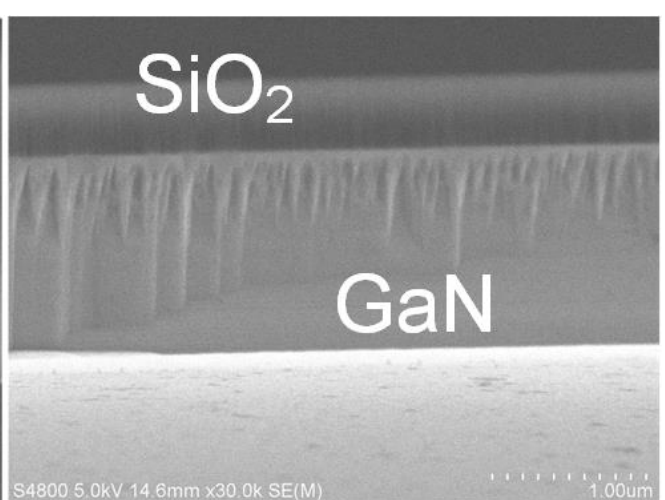

(b)

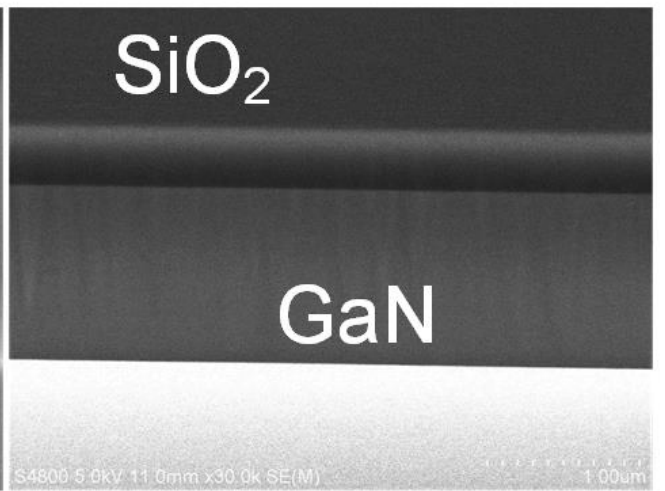

(d)

Figure 12. SEM micrographs of $\mathrm{SiO}_{2}$-masked $\mathrm{GaN}$ etched with the optimum ICP etching recipe before tetramethylammonium hydroxide (TMAH) wet treatment. (a) Cross-sectional view of the sidewall; (b) sidewall surface. After TMAH wet treatment: (c) cross-sectional view of the sidewall; (d) sidewall surface.

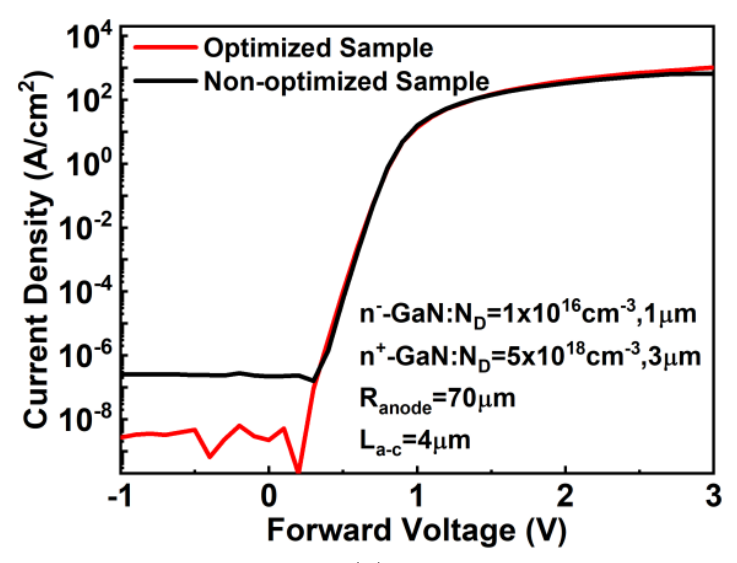

(a)

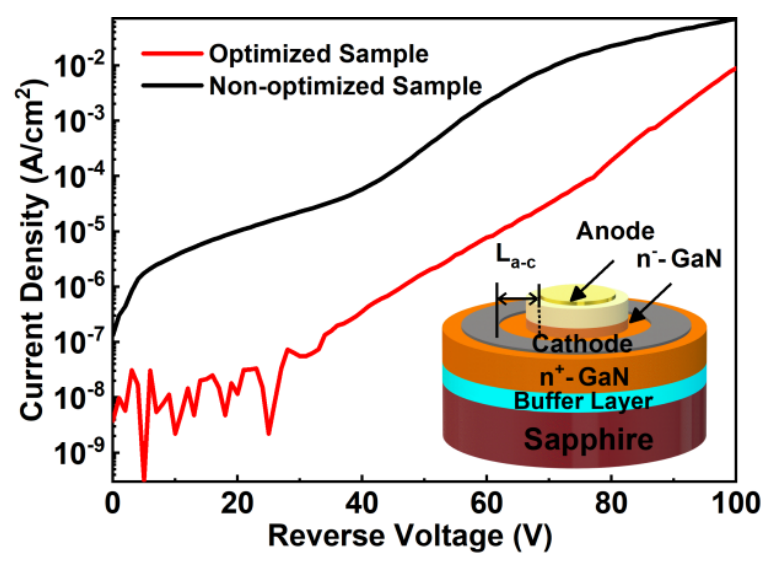

(b)

Figure 13. (a) Forward and (b) reverse $I-V$ characteristics of the optimized and non-optimized quasi-vertical GaN SBDs in this study. The inset of (b) shows a 3D schematic of the SBD. $\mathrm{R}_{\text {anode }}$ and $\mathrm{L}_{\mathrm{a}-\mathrm{c}}$ are the anode radius and the distance between the anode edge and cathode, respectively.

\section{Conclusions}

In summary, the influence of ICP etching conditions on GaN mesa sidewall profiles was studied and quasi-vertical GaN SBDs were fabricated using the optimized recipe. For the PR-masked GaN samples, high ICP power and RF power are the causes of deteriorated mesa sidewall morphology. Although high-temperature $\left(>140^{\circ} \mathrm{C}\right)$ hard baking prior to etching can produce a smooth sidewall, 
the drawbacks are significant oblique sidewall profile formation and hard striping. For the $\mathrm{SiO}_{2}$-masked GaN samples, the etching rate of GaN is dependent on the ICP power, RF power, and ratio of $\mathrm{BCl}_{3} / \mathrm{Cl}_{2}$ gas flow, but has relatively less dependence on the chamber pressure. The etching selectivity of $\mathrm{GaN}$ over $\mathrm{SiO}_{2}$ decreases with increasing $\mathrm{BCl}_{3}$ concentration in $\mathrm{Cl}_{2} / \mathrm{BCl}_{3}$ mixture gas in the range of $0-40 \%$. The etching selectivity of $\mathrm{GaN} / \mathrm{SiO}_{2}$ can be increased by adjusting the chamber pressure. Moreover, the microtrench problem at the bottom corner of the mesa can be reduced or eliminated by reducing the ICP power or RF power or by adding $\mathrm{BCl}_{3}$ into the $\mathrm{Cl}_{2}$ plasma. After ICP etching, the use of a TMAH wet treatment for samples can obtain a near- $90^{\circ}$ steep mesa sidewall that is microtrench free and has a smooth sidewall surface.

Therefore, the optimized ICP etching recipe is as follows: $360 \mathrm{~W}$ ICP power, $42 \mathrm{~W}$ RF power, $118 \mathrm{sccm} / 12 \mathrm{sccm} \mathrm{Cl} / \mathrm{BCl}_{3}$ flow rates, 1.5 Pa chamber pressure, and subsequent treatment with $15 \%$ concentration TMAH at $45^{\circ} \mathrm{C}$ for 30 min. Finally, quasi-vertical GaN-on-sapphire SBDs with $1.2 \mu \mathrm{m}$ mesa depth were fabricated using the optimized etching recipe, and the device characteristics were demonstrated to achieve a low reverse leakage current density of $10^{-8} \mathrm{~A} / \mathrm{cm}^{2}$ at $-10 \mathrm{~V}$, suggesting that the damage to the mesa sidewall is low.

Author Contributions: Y.S. and X.K. contributed equally to this paper. Writing-original draft, Y.S.; Writing-review \& editing, X.K.; Data curation, P.L. and W.W.; Project administration, X.K., Y.Z. and K.W.; Supervision, G.Z. and $X . L$. All authors have read and agreed to the published version of the manuscript.

Funding: This work was supported by the National Key Research and Development Program of China (Grant No. 2017YFB0403000 and 2016YFB0400100) and the Natural Science Foundation of China (Grant No. 61804172 and 61534007), in part by the Youth Innovation Promotion Association of CAS, and in part by the Key-Area Research and Development Program of GuangDong Province (No. 2019B010128001).

Acknowledgments: The authors would like to thank the co-support of the Shenzhen Institute of Wide-bandgap Semiconductors (iWins) and the Institute of Microelectronics of the Chinese Academy of Sciences (IMECAS). The authors also would like to thank Runze Zhang, Xueqin Lv, Dahai Wang, Wei Yue, Weichao Wu, Bin Wang, Aixue Zhang, and Yang Liu in IMECAS for the technical support.

Conflicts of Interest: The authors declare no conflict of interest.

\section{References}

1. Baliga, B.J. Gallium nitride devices for power electronic applications. Semicond. Sci. Technol. 2013, $28,074011$. [CrossRef]

2. Yuhao, Z.; Min, S.; Piedra, D.; Hennig, J.; Dadgar, A.; Palacios, T. Reduction of on-resistance and current crowding in quasi-vertical GaN power diodes. Appl. Phys. Lett. 2017, 111, 163506.

3. Oka, T. Recent development of vertical GaN power devices. Jpn. J. Appl. Phys. 2019, 58, SB0805. [CrossRef]

4. Sun, Y.; Kang, X.; Zheng, Y.; Lu, J.; Tian, X.; Wei, K.; Wu, H.; Wang, W.; Liu, X.; Zhang, G. Review of the Recent Progress on GaN-Based Vertical Power Schottky Barrier Diodes (SBDs). Electronics 2019, 8, 575. [CrossRef]

5. Zhang, Y.; Sun, M.; Wong, H.; Lin, Y.; Srivastava, P.; Hatem, C.; Azize, M.; Piedra, D.; Yu, L.; Sumitomo, T.; et al. Origin and Control of OFF-State Leakage Current in GaN-on-Si Vertical Diodes. IEEE Trans. Electron Devices 2015, 62, 2155-2161. [CrossRef]

6. Han, C.; Zhang, Y.; Song, Q.; Zhang, Y.; Tang, X.; Yang, F.; Niu, Y. An Improved ICP Etching for Mesa-Terminated 4H-SiC p-i-n Diodes. IEEE Trans. Electron Devices 2015, 62, 1223-1229. [CrossRef]

7. Rawal, D.S.; Arora, H.; Agarwal, V.R.; Vinayak, S.; Kapoor, A.; Sehgal, B.K.; Muralidharan, R.; Saha, D.; Malik, H.K. GaN etch rate and surface roughness evolution in $\mathrm{Cl}_{2}$ /Ar based inductively coupled plasma etching. Thin Solid Film. 2012, 520, 7212-7218. [CrossRef]

8. Yang, G.F.; Chen, P.; Wu, Z.L.; Yu, Z.G.; Zhao, H.; Liu, B.; Hua, X.M.; Xie, Z.L.; Xiu, X.Q.; Han, P.; et al. Characteristics of $\mathrm{GaN}$ thin films by inductively coupled plasma etching with $\mathrm{Cl}_{2} / \mathrm{BCl}_{3}$ and $\mathrm{Cl}_{2} / \mathrm{Ar}$. J. Mater. Sci. Mater. Electron. 2012, 23, 1224-1228. [CrossRef]

9. Rawal, D.S.; Sehgal, B.K.; Muralidharan, R.; Malik, H.K.; Dasgupta, A. Effect of $\mathrm{BCl}_{3}$ concentration and process pressure on the $\mathrm{GaN}$ mesa sidewalls in $\mathrm{BCl}_{3} / \mathrm{Cl}_{2}$ based inductively coupled plasma etching. Vacuum 2012, 86, 1844-1849. [CrossRef]

10. Sheu, J.K.; Su, Y.K.; Chi, G.C.; Jou, M.J.; Liu, C.C.; Chang, C.M.; Hung, W.C. Inductively coupled plasma etching of $\mathrm{GaN}$ using $\mathrm{Cl}_{2} / \mathrm{Ar}$ and $\mathrm{Cl}_{2} / \mathrm{N}_{2}$ gases. J. Appl. Phys. 1999, 85, 1970-1974. [CrossRef] 
11. Li, X.L.; Ma, P.; Ji, X.L.; Wei, T.B.; Tan, X.Y.; Wang, J.X.; Li, J.M. Implementation of slow and smooth etching of GaN by inductively coupled plasma. J. Semicond. 2018, 39, 6. [CrossRef]

12. Chang, L.B.; Liu, S.S.; Jeng, M.J. Etching selectivity and surface profile of $\mathrm{GaN}$ in the $\mathrm{Ni}, \mathrm{SiO}_{2}$ and photoresist masks using an inductively coupled plasma. Jpn. J. Appl. Phys. Part 1 Regul. Pap. Short Notes Rev. Pap. 2001, 40, 1242-1243. [CrossRef]

13. Hahn, H.; Gruis, J.B.; Ketteniss, N.; Urbain, F.; Kalisch, H.; Vescan, A. Influence of mask material and process parameters on etch angle in a chlorine-based GaN dry etch. J. Vac. Sci. Technol. A Vac. Surf. Film. 2012, 30, 051302. [CrossRef]

14. Zhao, Y.F.; Hu, W.; Wei, Z.; Li, J.D.; Yang, S.; Huang, Z.L.; Jian, Z.; An, D.S. Controllable process of nanostructured GaN by maskless inductively coupled plasma (ICP) etching. J. Micromech. Microeng. 2017, 27, 7. [CrossRef]

15. Efremov, A.; Min, N.-K.; Choi, B.-G.; Baek, K.-H.; Kwon, K.-H. Model-Based Analysis of Plasma Parameters and Active Species Kinetics in $\mathrm{Cl}_{2} / \mathrm{X}\left(\mathrm{X}=\mathrm{Ar}, \mathrm{He}, \mathrm{N}_{2}\right)$ Inductively Coupled Plasmas. J. Electrochem. Soc. 2008, 155, D777-D782. [CrossRef]

16. Rawal, D.S.; Arora, H.; Sehgal, B.K.; Muralidharan, R. Comparative study of GaN mesa etch characteristics in $\mathrm{Cl}_{2}$ based inductively coupled plasma with $\mathrm{Ar}$ and $\mathrm{BCl} 3$ as additive gases. J. Vac. Sci. Technol. A 2014, 32, 10. [CrossRef]

17. Liu, Z.; Wang, Y.J.; Xia, X.X.; Yang, H.F.; Li, J.J.; Gu, C.Z. Fabrication of GaN hexagonal cones by inductively coupled plasma reactive ion etching. J. Vac. Sci. Technol. B 2016, 34, 4. [CrossRef]

18. Pearton, S.J.; Zolper, J.C.; Shul, R.J.; Ren, F. GaN: Processing, defects, and devices. J. Appl. Phys. 1999, 86, 1-78. [CrossRef]

19. Reflow of Photoresist. Available online: https://www.microchemicals.com/technical_information/reflow_ photoresist.pdf (accessed on 24 February 2020).

20. Liu, H.; Herrnsdorf, J.; Gu, E.; Dawson, M.D. Control of edge bulge evolution during photoresist reflow and its application to diamond microlens fabrication. J. Vac. Sci. Technol. B Nanotechnol. Microelectron. Mater. Process. Meas. Phenom. 2016, 34, 021602. [CrossRef]

21. O'neill, F.T.; Sheridan, J.T. Photoresist reflow method of microlens production Part I: Background and experiments. Optik 2002, 113, 391-404. [CrossRef]

22. Cui, Z. Basics of Photoresists. In Nanofabrication, 2nd ed.; Springer: Berlin/Heidelberg, Germany, 2017; Volume 17.

23. Rubico Jay, T.; Stern, M. Preshaping photoresist for refractive microlens fabrication. Opt. Eng. 1994, 33, 3552-3556.

24. Mahorowala, A.P. Feature Profile Evolution during the High-Density Plasma Etching of Polysilicon. Ph.D. Thesis, Massachusetts Institute of Technology, Cambridge, MA, USA, 20 August 1998.

25. Watanabe, M.; Shaw, D.M.; Collins, G.J. Reduction of microtrenching and island formation in oxide plasma etching by employing electron beam charge neutralization. Appl. Phys. Lett. 2001, 79, 2698-2700. [CrossRef]

26. Smith, S.A.; Wolden, C.A.; Bremser, M.D.; Hanser, A.D.; Davis, R.F.; Lampert, W.V. High rate and selective etching of GaN, AlGaN, and AlN using an inductively coupled plasma. Appl. Phys. Lett. 1997, 71, 3631-3633. [CrossRef]

27. Zhou, S.; Cao, B.; Liu, S. Optimized ICP etching process for fabrication of oblique GaN sidewall and its application in LED. Appl. Phys. A Mater. Sci. Process. 2011, 105, 369-377. [CrossRef]

28. Turner, M.M.; Lieberman, M.A. Hysteresis and the E-to-H transition in radiofrequency inductive discharges. Plasma Sources Sci. Technol. 1999, 8, 313-324. [CrossRef]

29. Kempkes, P.; Singh, S.V.; Pargmann, C.; Soltwisch, H. Temporal behaviour of the e to H mode transition in an inductively coupled argon discharge. Plasma Sources Sci. Technol. 2006, 15, 378-383. [CrossRef]

30. Cooke, M.J.; Hassall, G. Low-pressure plasma sources for etching and deposition. Plasma Sources Sci. Technol. 2002, 11, A74-A79. [CrossRef]

31. Qiu, R.F.; Lu, H.; Chen, D.J.; Zhang, R.; Zheng, Y.D. Optimization of inductively coupled plasma deep etching of GaN and etching damage analysis. Appl. Surf. Sci. 2011, 257, 2700-2706. [CrossRef]

32. Kim, B.; Bae, J.; Teak Lee, B. Microtrench depth and width of SiON plasma etching. Vacuum 2006, 81, 338-343. [CrossRef]

33. Kim, H.S.; Yeom, G.Y.; Lee, J.W.; Kim, T.I. Characteristics of inductively coupled $\mathrm{Cl}_{2} / \mathrm{BCl}_{3}$ plasmas during GaN etching. J. Vac. Sci. Technol. A 1999, 17, 2214-2219. [CrossRef] 
34. Wang, T.B.; Hsu, W.C.; Che, Y.W.; Chen, Y.J. Inductively coupled plasma mesa etched InGaN/GaN light emitting diodes using $\mathrm{Cl}_{2} / \mathrm{BCl}_{3} / \mathrm{Ar}$ plasma. Jpn. J. Appl. Phys. Part 1 Regul. Pap. Brief Commun. Rev. Pap. 2006, 45, 6800-6802. [CrossRef]

35. Lee, Y.H.; Kim, H.S.; Yeom, G.Y.; Lee, J.W.; Yoo, M.C.; Kim, T.I. Etch characteristics of GaN using inductively coupled $\mathrm{Cl}_{2} / \mathrm{Ar}$ and $\mathrm{Cl}_{2} / \mathrm{BCl}_{3}$ plasmas. J. Vac. Sci. Technol. Vac. Surf. Film. 1998, 16, 1478-1482. [CrossRef]

36. Zhou, S.J.; Cao, B.; Liu, S. Dry etching characteristics of $\mathrm{GaN}$ using $\mathrm{Cl}-2 / \mathrm{BCl} 3$ inductively coupled plasmas. Appl. Surf. Sci. 2010, 257, 905-910. [CrossRef]

37. Lee, Y.H.; Sung, Y.J.; Yeom, G.Y.; Lee, J.W.; Kim, T.I. Magnetized inductively coupled plasma etching of GaN in Cl2/BCl3 plasmas. J. Vac. Sci. Technol. A Vac. Surf. Film. 2000, 18, 1390-1394. [CrossRef]

38. Kim, B.; Kim, J.; Lee, S.; Park, J.; Lee, B. Plasma etching of silicon oxynitride in a low-pressure C 2 F 6 plasma. J. Korean Phys. Soc. 2005, 47, 712-715.

39. Abdollahi-Alibeik, S.; Mcvittie, J.P.; Saraswat, K.C.; Sukharev, V.; Schoenborn, P. Analytical modeling of silicon etch process in high density plasma. J. Vac. Sci. Technol. A Vac. Surf. Film. 1999, 17, 2485-2491. [CrossRef]

40. Sarangan, A. Wet Chemical and Plasma Etching. In Nanofabrication: Principles to Laboratory Practice, 1st ed.; Taylor \& Francis Group: Boca Raton, FL, USA, 2016; pp. 235-237.

41. Ladroue, J.; Meritan, A.; Boufnichel, M.; Lefaucheux, P.; Ranson, P.; Dussart, R. Deep GaN etching by inductively coupled plasma and induced surface defects. J. Vac. Sci. Technol. A 2010, 28, 1226-1233. [CrossRef]

42. Wang, P.; Cao, B.; Gan, Z.Y.; Liu, S. A Study of GaN-Based LED Structure Etching Using Inductively Coupled Plasma. In 3rd International Photonics and Optoelectronics Meetings; Ye, C., Wang, Z.L., Zhou, B., Eds.; IOP Publishing Ltd.: Bristol, UK, 2011.

43. Awan, K.M.; Muhammad, M.M.; Sivan, M.; Bonca, S.; Roqan, I.S.; Dolgaleva, K. Fabrication and optical characterization of $\mathrm{GaN}$ waveguides on (-201)-oriented $\beta-\mathrm{Ga}_{2} \mathrm{O}_{3}$. Opt. Mater. Express 2017, 8, 88-96. [CrossRef]

44. He, J.; Feng, M.; Zhong, Y.; Wang, J.; Zhou, R.; Gao, H.; Zhou, Y.; Sun, Q.; Liu, J.; Huang, Y.; et al. On-wafer fabrication of cavity mirrors for InGaN-based laser diode grown on Si. Sci. Rep. 2018, 8, 7922. [CrossRef]

45. Wan, H.; Tang, B.; Li, N.; Zhou, S.; Gui, C.; Liu, S. Revealing the Role of Sidewall Orientation in Wet Chemical Etching of GaN-Based Ultraviolet Light-Emitting Diodes. Nanomaterials 2019, 9, 365. [CrossRef]

46. Chen, J.; Bian, Z.; Liu, Z.; Ning, J.; Duan, X.; Zhao, S.; Wang, H.; Tang, Q.; Wu, Y.; Song, Y.; et al. High-performance quasi-vertical GaN Schottky barrier diode with anode selective fluorine treatment. Semicond. Sci. Technol. 2019, 34, 115019. [CrossRef]

47. Li, Y.; Wang, M.; Yin, R.; Zhang, J.; Tao, M.; Xie, B.; Hao, Y.; Yang, X.; Wen, C.P.; Shen, B. Quasi-Vertical GaN Schottky Barrier Diode on Silicon Substrate with $10^{10}$ High On/Off Current Ratio and Low Specific On-Resistance. IEEE Electron Device Lett. 2020, 41, 329-332. [CrossRef]

48. Hashimoto, S.; Yoshizumi, Y.; Tanabe, T.; Kiyama, M. High-purity GaN epitaxial layers for power devices on low-dislocation-density GaN substrates. J. Cryst. Growth 2007, 298, 871-874. [CrossRef]

49. Cao, Y.; Chu, R.; Li, R.; Chen, M.; Williams, A.J. Improved performance in vertical GaN Schottky diode assisted by AlGaN tunneling barrier. Appl. Phys. Lett. 2016, 108, 112101. [CrossRef]

50. Kang, X.; Wang, X.; Huang, S.; Zhang, J.; Liu, X. Recess-free AlGaN/GaN lateral Schottky barrier controlled Schottky rectifier with low turn-on voltage and high reverse blocking. In Proceedings of the 2018 IEEE 30th International Symposium on Power Semiconductor Devices and ICs (ISPSD), Chicago, IL, USA, 13-17 May 2018.

(C) 2020 by the authors. Licensee MDPI, Basel, Switzerland. This article is an open access article distributed under the terms and conditions of the Creative Commons Attribution (CC BY) license (http://creativecommons.org/licenses/by/4.0/). 